\title{
Elektif Sezaryen Vakalarında Genel ve Spinal Anestezinin Hasta Memnuniyeti Açısından Karşılaştırılması
}

\section{Comparison of General and Spinal Anesthesia in Elective Cesarean Section in Terms of Patient Satisfaction}

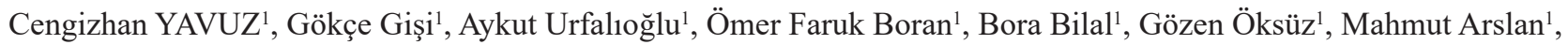
Hafize Öksüz1 ${ }^{1}$ Hüseyin Yıldız², Şeyma Bahar ${ }^{3}$

\footnotetext{
${ }^{1}$ Sütçü İmam Üniversitesi, Tıp Fakültesi Anesteziyoloji ve Reanimasyon Anabilim Dalı, Kahramanmaraş, Türkiye

${ }^{2}$ Medical park Gaziantep Hastanesi, Gaziantep, Türkiye

${ }^{3}$ Kahramanmaraş Necip Fazıl Şehir Hastanesi Kadın Doğum ve Çocuk Ek Hizmet Binası, Kahramanmaraş, Türkiye
}

\section{Özet}

Amaç: Elektif sezaryenlerde spinal ve genel anesteziyi anne memnuniyeti açısından kıyaslamayı amaçladık.Ek olarak hastaların kaygı düzeylerinin anestezi yöntemi seçimine etkisini araştırdık.

Gereç ve Yöntemler: Elektif sezaryen ile opere olan 101 gönüllü hasta prospektif olarak araştırıldı. Hastalar anestezi yöntemlerini kendileri tercih etti. Spinal anesteziyi tercih eden 51, genel anesteziyi tercih eden 50 hasta araștırıldı. Hastaların operasyon öncesi anestezi ile ilgili endișeleri soruldu. Operasyon öncesi kaygı düzeyleri Durumluluk-Süreklilik Kaygı Ölçeği (STAI= State-Trait Anxiety Inventory) ile tespit edildi. Operasyondan 24 saat sonra komplikasyonlar sorgulandı ve memnuniyet düzeyi ölçümü için ameliyat sonrası iyileșme kalitesini ölçen Memnuniyet-Derlenme Kalitesi Ölçeği (QoR-40= Quality of Recovery-40) anketi hastalara uyguland1.

Bulgular: Genel anesteziyi tercih eden hastaların kaygı düzeyi daha yüksek bulundu (p:0.000). Hastaların anesteziden en büyük endişeleri ameliyat sonrası uyanmamak (\%53.5), yoğun bakımda kalmak (\%18.8), ameliyat sonrası ağrı (\%11.9) olarak tespit edildi. Postoperatif komplikasyonlardanbulantı-kusma, bel, sırt ağrısı ve nefes darlı̆̆ı gelişen hastaların QoR-40 değerlerinin istatistiksel olarak anlamlı düşük olduğu gözlenmiştir. Spinal anestezi ile opere olan hastaların QoR-40 puanları daha yüksekti (p:0.014)

Sonuç: Spinal anestezi ile opere olan hastaların daha memnun oldukları tespit edildi. Genel anesteziyi tercih eden hastaların kaygı düzeylerinin daha yüksek olduğu görüldü.

Anahtar kelimeler: Sezaryen, Genel anestezi, Spinal anestezi, Anksiyete, Memnuniyet

\section{Abstract}

Objective: We aimed to compare spinal and general anesthesia in terms of maternal satisfaction in elective cesarean sections. In addition we investigated the effect of patients' anxiety levels on the choice of anesthesia method.

Material and Methods: 101 volunteer patients undergoingelective cesarean section were prospectively investigated. The patients preferred the anesthesia methods themselves. 51 patients who preferred spinal anesthesia and 50 patients who preferred general anesthesia were investigated. The patients were asked about their concerns about anesthesia before the operation. Anxiety levels before the operation were determined with the State-Trait Anxiety Inventory (STAI). 24 hours after the operation, Quality of Recovery-40 Scale was used to evaluate their satisfaction levels. And possible complications were questioned.

Results: The anxiety level of the patients who preferred general anesthesia was found to be higher (p:0.000). The biggest fears of the patientsaboutanesthesia were not waking up after surgery (53.5\%), staying in the intensive care unit (18.8\%), and post-operative pain (11.9\%). It was observed that the QoR-40 values of the patients who developed postoperative complications such as nausea-vomiting, low back pain and shortness of breath were statistically significantly lower. The QoR-40 scores of the patients who were operated under spinal anesthesia were higher (p:0.014).

Conclusion: We found that patients who were operated under spinal anesthesia were more satisfied. It was observed that those who preferred general anesthesia had higher anxiety levels.

Key words: Cesarean section, General anesthesia, Spinal anesthesia, Anxiety, Satisfaction

Yazışma Adresi: Cengizhan YAVUZ, Sütçü İmam Üniversitesi, Tıp Fakültesi, Anesteziyoloji ve Reanimasyon Anabilim Dalı, Kahramanmaraş, Türkiye Telefon: +0 34430033 75-0543 48433 29, Mail: cengizhanyavuz@windowslive.com

ORCID No(sırasıyla): 0000-0003-4627-7403, 0000-0003-1863-6878, 0000-0002-0657-7578, 0000-0002-0262-9385, 0000-0003-3884-8042, 0000-00015197-8031, 0000-0002-2820-1547, 0000-0002-6156-4607, 0000-0003-0852-774X, 0000-0003-3498-9606

Gelis Tarihi: 08.06 .2021

Kabul Tarihi: 12.08.2021

DOI: $10.17517 /$ ksutfd.949441 


\section{GIRIŞ}

Günümüzde sezaryen oranları giderek artmakta olup Türkiye Halk Sağlığı kurumunun sonuçlarına göre 2019 yılında sezaryen ameliyatının canlı doğumlar içindeki oranı \% 54.4 olmuştur (1). Anestezistin sezaryen operasyonlarında optimal anestezi ve analjezi sağlayabilmesi için; gebeliğin ve doğumun fizyolojik değişikliklerini, anestezik ajanların fetüs ve yenidoğan üzerindeki direkt ve indirekt etkilerini, değişik anestezi tekniklerinin risk ve yararlarını ve anestezi uygulamalarındaki obstetrik komplikasyonların önemini iyi bilmesi gerekmektedir. Tüm anne adayları için ideal bir anestezik yöntem yoktur. Anestezi seçimi; anne adayının isteğine, obstetrik ihtiyaca ve anestezistin deneyimine bağlıdır (2).

Spinal anestezi epidural anesteziye göre daha hızlı yapılabilmesi, kuvvetli duyu ve motor bloğu ile ideal ameliyat koşulları oluşturması, düşük dozlar kullanıldığından lokal anestezik toksisite riskinin düşük olması ve bebeğe ilaç geçişinin minimal olması gibi avantajları nedeniyle daha çok tercih edilmektedir (3). Genel anestezi ise çok hılı ve güvenilir başlangıca sahip olması, sempatik blok ve hipotansiyon yapmaması açısından avantajlı olmasına karşın; pulmoner aspirasyon riski, hastanın entübe veya ventile edilememesi ve ilaçların fetal depresyona neden olabilmesi gibi risklere sahiptir (4). Sezaryen doğum için modern anestezik bakım son derece güvenli olsa da hava yolu yönetimindeki güçlükler nedeniyle, genel anestezide görülen komplikasyon oranı bölgesel anestezide görülen komplikasyon oranınından daha fazladır (5). Hastaların anestezi ile ilgili endişeleri ve yüksek anksiyete düzeylerinin anestezi yöntemi seçimini etkileyebileceğini düşünerek planladığımız çalışmamızda elektif sezaryen yapılan miadında gebelerde preoperatif kaygı düzeylerini ölçerek, spinal anestezi altında sezaryen uygulanan olgular ile genel anestezi altında sezaryen yapılan olguları hasta memnuniyeti açısından karşılaştırdık. Ortaya çıkacak sonuçlar ışığında; elektif sezaryen olgularında anne konforunun arttırılabilmesi noktasında genel anestezi ve spinal anestezinin günümüz itibarı ile ulaştığı düzeyin hasta memnuniyeti üzerinden değerlendirilmesi hedeflenmiştir.

\section{GEREÇ VE YÖNTEMLER}

Üniversite yerel etik kurulunun onayı (Sütçü İmam Üniversitesi Tip Fakültesi 2015; protokol no: 01; karar no:03) alındıktan sonra Şubat 2015-Nisan 2015 tarihlerinde elektif sezaryen operasyonuna alınan 15-49 yaş arası ASA-1 ve ASA-2 sınıfı gebelerastgele yöntemle seçilerek çalışmaya dahil edildi. Bu kapsamda elektif sezaryene alınan genel anestezi yöntemiyle 50 hasta, spinal anestezi yöntemiyle 51 hasta çalışmaya alınarak, örneklem 101 hastadan oluşturulmuştur. $\mathrm{Bu}$ çalışma Helsinki Deklerasyonu prensiplerine uygun olarak gerçekleştirilmiştir.

Çalışmamızda hastaların kaygı düzeylerini ölçmek için STAI (State-Trait Anxiety Inventory = Durumluluk-Süreklilik Kaygı Ölçeği) kullandık. STAI durumluluk ve süreklilik kaygı düzeylerini değerlendiren yirmişer soruluk iki ölçekten oluşmaktadır.
Anestezi öncesi muayene sırasında onamı alınan hastaların, STAI ᄀ-2 kaygı ölçeği formu doldurularak süreklilik kayg1 ölçeği puanları tespit edildi.Ayrıca gebelerin eğitim düzeyi, çalışma durumu, daha önceki anestezi deneyimi ve gebelik sayısı kaydedildi. Hastalara preoperatif anestezi ile ilgili endişelerinin olup olmadığg soruldu ve en çok endişe ettiği ilk üç neden not edildi.

Ameliyat günü preoperatif hazırlık odasında hastalardan STAI-1 durumluluk kaygı ölçeğini doldurmaları istendi. Kullanılan bu iki ölçekte deelde edilen toplam puan 20 ile 80 arasında değişmekte ve büyük puan yüksek kaygı seviyesini, küçük puan ise düşük kaygı seviyesini göstermektedir.

Yöntemler hakkında bilgilendirme sonrası genel veya spinal anestezi arasında kendi seçimini yapanhastalara $500 \mathrm{cc}$ \%0.9 sodyum klorürlü izotonik mayi verildi ve premedikasyon yapildı. Ameliyathane odasına alınan hastalara standart noninvaziv monitörizasyon yapıldı. Genel anesteziyi tercih eden hastalar preoksijenasyon sonrası $2 \mathrm{mg} / \mathrm{kg}$ propofol ve $1.5 \mathrm{mg} / \mathrm{kg}$ süksinilkolin indüksiyonu sonrasientübe edildi. Bebeğin çıkımıyla birlikte sevofluran ile anesteziye devam edildi ve postoperatif ağrı için fetüs çıkımından sonra 0.5 $\mathrm{mg} / \mathrm{kg}$ tramodol uyguland. Operasyon bitiminde spontan solunumu dönen hasta ekstübe edilip uyandırıldı. Sonrasında postoperatif takip odasına alınıp, servise gönderildi.

Spinal anesteziyi tercih eden hastalara monitörizasyon sonrası oturur pozisyonda medyan yaklaşımla,27 gauge pencil point veya 25 gauge quincke uçlu spinal iğne ile subaraknoid aralığa 10-12 mg marcaine spinal heavy verilerek spinal anestezi uygulandi. Spinal anestezi düzeyi kontrol edildi ve yeterli duyu alanına ulaşılması ile operasyona başlandı. Her iki gruptada intraoperatif hemodinamik parametreler, efedrin ihtiyacı kaydedildi.

Postoperatif 24. saatte tüm hastalar serviste ziyaret edildi ve 40-200 arasında puanlanan QoR-40 (Quality of Recovery-40) hasta memnuniyet derlenme kalitesi ölçeği dolduruldu. Myles tarafından geliştirilen QoR-40 emosyonel durum, fiziksel konfor, psikolojik destek, fiziksel bağımlılık ve ağrı alt komponentlerini içerir. 40 sorudan oluşur. Ayrıca hastalarda oluşabilecek ve memnuniyetsizliğe neden olabilecek komplikasyonlar sorguland.

\section{İstatistiksel Analiz}

İstatistiksel değerlendirmeler için SPSS for Windows 20.0 Türkçe paket programı kullanılmıştır. Verilerin normal dağllıma uygunluk analizi Kolmogrov-Smirnov testi ile yapıldı. Tanımlayıcı istatistikler ortalama \pm standart sapma ve $\%$ ile ifade edildi. Kategorik değişkenlerin karşılaştırılması için Ki Kare, gruplar arası karşılaştırmalarda Student t testi kullanıldi. $\mathrm{p}<0.05$ anlamlılık düzeyi olarak kabul edildi.

\section{SONUÇLAR}

Çalışmaya alınan hastaların yaş ortalaması $29.7 \pm 5.59$ olarak,ağırlık ortalaması $77.79 \pm 12.2$ olarak tespit edildi. Hastaların eğitim düzeyi, çalışma durumu ve anestezi deneyimi olup olmaması ile anestezi yöntemi seçimi arasında istatiksel 
olarak anlamlı fark bulunmadı, ancak tabloda görüldüğü gibi spinal anesteziyi seçenlerin gebelik sayısı, genel anesteziyi seçen hastalardan anlamlı olarak fazlaydı (Tablo 1).

\section{Tablo 1. Demografik özelliklerine göre anestezi yöntemi seçimi}

\begin{tabular}{|l|c|c|c|} 
& Genel anestezi & Spinal anestezi & $\mathbf{p}$ \\
\hline Yaş & $28,4 \pm 4,8$ & $30,9 \pm 6$ & 0,029 \\
\hline Boy & $158,3 \pm 4,5$ & $159,8 \pm 6,1$ & 0,171 \\
\hline Ağırlık & $76,3 \pm 10,8$ & $79,2 \pm 13,5$ & 0,228 \\
\hline Gebelik sayısı & $2,7 \pm 1,19$ & $3,3 \pm 1,15$ & 0,029 \\
\hline
\end{tabular}

Genel anesteziyi tercih eden hastaların STAI-1 puanlarının ortalama değeri 53.08 \pm 7.92 iken spinal anestezide $47.15 \pm 6.65$ idi (Tablo 2). Bu fark istatiksel olarak anlaml bulunmuştur (p:0.000). STAI-2' de ise durum genel anestezide $42.06 \pm 4.88$ iken spinal anestezide $43.19 \pm 3.93$ olup, bu değerler arasında anlamlı fark bulunmadı̆̆ 1 tespit edilmiştir (p:0.201). Genel anestezi ile opere olan hastaların QoR-40 değerlerinin ortalaması $170.60 \pm 11.06$ tespit edilmiştir. Spinal anestezide ise bu değer $175.33 \pm 7.75$ idi. Bu fark istatiksel olarak anlamlı bulunmuştur (p:0.014).

\begin{tabular}{|c|c|c|c|}
\hline & STAI-1 & STAI-2 & QoR-40 \\
\hline Genel anestezi & $53,08 \pm 7,92$ & $42,06 \pm 4,88$ & $\begin{array}{c}170,60 \pm \\
11,06\end{array}$ \\
\hline $\begin{array}{l}\text { Spinal } \\
\text { anestezi }\end{array}$ & $47,15 \pm 6,65$ & $43,19 \pm 3,93$ & $175,33 \pm 7,75$ \\
\hline p & 0,000 & 0,201 & 0,014 \\
\hline
\end{tabular}

İntraoperatif hemodinamik veriler karşılaştırıldığında sistolik kan basıncının 5. dk da, diastolik ve ortalama kan basincının 5. 15. ve 30. dk da spinal anestezide anlamlı olarak düşük bulunduğu görülmüştür $(\mathrm{p}<0.005)$.Spinal anestezi yapılan 51 hastanın 24'ünde (\%47.1) hipotansiyon gelişmiş ve bu hastalara efedrin uygulanmıștır.

Tablo 3'de postoperatif komplikasyonların gruplara göre görülme sıklığı ve karşılaştırılması gösterilmiştir. Bilinç bulanıklığ ve nefes darlığ 1 istatiksel olarak anlamlı şekilde genel anestezi grubunda daha yüksek tespit edilmiştir.
Postoperatif komplikasyonların hasta memnuniyetine etkisini değerlendirmek için komplikasyon olan ve olmayan hastaların QoR-40 puan ortalamaları karşılaştırılmıştır (Tablo 4). Bulantı-kusma, bel sırt ağrısı ve nefes darlığı gelişen hastaların QoR-40 değerlerinin, gelişmeyenlere gör istatistiksel olarak anlamlı düşük olduğu gözlenmiştir

\begin{tabular}{|c|c|c|c|}
\hline & $\begin{array}{c}\text { Oldu } \\
(\text { QoR-40 ort } \pm \text { s.d. })\end{array}$ & $\begin{array}{c}\text { Olmadı } \\
(\text { QoR-40 ort } \pm \text { s.d. })\end{array}$ & $\mathbf{p}$ \\
\hline $\begin{array}{l}\text { Bulant1- } \\
\text { kusma }\end{array}$ & $167,8 \pm 9,0$ & $174,5 \pm 9,4$ & 0,003 \\
\hline $\begin{array}{l}\text { Bel sırt } \\
\text { ağrisı }\end{array}$ & $165,2 \pm 10,5$ & $175,9 \pm 7,6$ & 0,000 \\
\hline $\begin{array}{l}\text { Baş } \\
\text { dönmesi }\end{array}$ & $170,5 \pm 8,1$ & $173,3 \pm 9,9$ & 0,350 \\
\hline $\begin{array}{l}\text { Bilinç } \\
\text { bulanıklığı }\end{array}$ & $168,9 \pm 10,04$ & $173,4 \pm 9,7$ & 0,165 \\
\hline $\begin{array}{l}\text { Nefes } \\
\text { darlığı }\end{array}$ & $160,33 \pm 10,4$ & $175,1 \pm 7,8$ & 0,000 \\
\hline
\end{tabular}

Çalışmamızda anestezi öncesi endişe edilen birinci nedenler içinde en sık ameliyat sonrası uyanmamak (\% 53.5) işaretlenmiştir. Bunu sıklık sırasına göre yoğun bakımda kalmak (\%18.8), ameliyat sonrası ağrı (\%11.9) ve Şekil 1'de görülen diğer nedenler takip etmektedir.

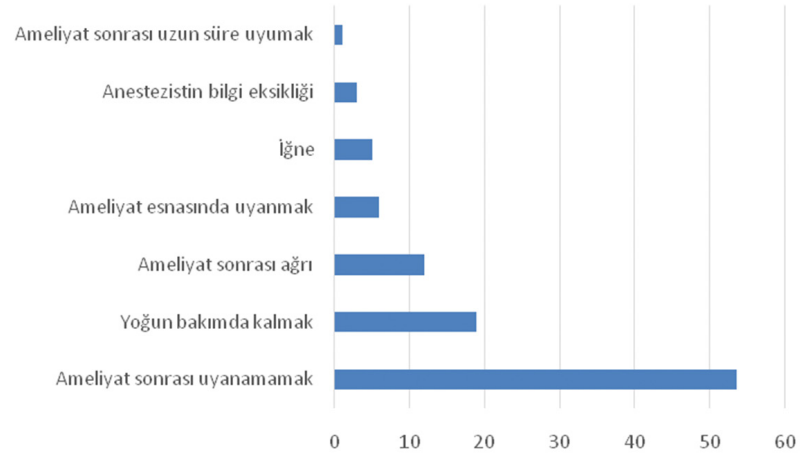

Şekil 1. Anestezi öncesi ilk sırada endişe edilen nedenlerin yüzdesi

Tablo 3.Postoperatif komplikasyonların gruplara göre görïlme sılklığı ve karşılaştırılması

\begin{tabular}{|l|c|c|c|}
\hline & Spinal anestezi $\mathbf{( n = 5 1 )} \mathbf{n}(\mathbf{\%})$ & Genel anestezi (n=50) $\mathbf{n}(\mathbf{\%})$ & $\mathbf{p}$ \\
\hline Bulantı-kusma & $9(17,6)$ & $15(30)$ & 0,145 \\
\hline Bel sırt ağrısı & $14(27,5)$ & $14(28)$ & 0,951 \\
\hline Baş dönmesi & $3(5,9)$ & $9(18)$ & 0,056 \\
\hline Bilinç bulanıklı̆̆ı & $0(0)$ & $10(20)$ & 0,001 \\
\hline Nefes darlı̆̆1 & $4(7,8)$ & $11(22)$ & 0,045 \\
\hline
\end{tabular}




\section{TARTIŞMA}

Çalışmamızda genel anesteziyi tercih eden hastaların STAI-1 (durumluluk) puanlarının anlamlı yüksek olduğu yani daha endişeli oldukları gözlenmiştir. Klinik deneyimlerimizde de özellikle acil vakalarda iyi bilgilendirilmemiş endişeli hastaların hiçbirşeyi görmek ve hissetmek istemediklerini söyleyerek genel anestezi almak istediklerini gözlemliyoruz. Bu hastalara yeterli bilgilendirme yapılarak endişeleri giderildiğinde ise spinal anesteziyi kabul ettiklerini görüyoruz. Maheshwari ve Ismail'in çalışmasında anestezist tarafından bilgi verilen hastalarda anksiyete oranı \%60.7 iken, anestezist olmayan biri tarafından bilgi verildiğinde bu oran \%89.2'dir ve bu fark anlamlı bulunmuştur. Yine aynı çalışmada anksiyöz hastalar içinde anestezist tarafından bilgilendirilen hastaların spinal anestezi tercih oranı \%68.5 iken anestezist olmayan biri tarafindan bilgilendirilen hastalarda bu oran \%10.3'tür (6). Jlala ve arkadaşlarının yapmış oldukları çalışmada ise multimedya ile bilgilendirme yapılan hastaların perioperatif anksiyetelerine bakıldığında, multimedya ile bilgilendirme yapılan grupta, kontrol grubuna göre preoperatif ve postoperatif anksiyete skorları anlamlı düşük bulunmuş (7). Bu sonuçlar da bize yeterli bilgilendirme ile hastaların ameliyat ile ilgili endişelerinin azaltılabileceğini ve böyleliklespinal anestezi tercih oranlarının artırılabileceğini göstermektedir.

Havas ve arkadaşlarının yaptığı bir çalışmada spinal anestezi altında yapılan sezaryen olgularında hipotansiyon insidansı $\% 45.7$ olarak tespit edilmiştir ve hastaların \%42.6'sında efedrin ihtiyacı olduğu bildirilmiştir (8). Aynı çalışmada spinal ile genel anestezi arasında sistolik kan basıncı kıyaslanmış, 3. ve 6. dakikalarda ve operasyon sonunda sistolik kan basıncının spinal anestezide, genel anesteziye oranla anlamlı düşük olduğu gözlenmiştir. Purtuloğlu ve arkadaşlarının çalışmasında spinal ve genel anestezi arasında 5, 10, 15, 20, 25. dakika ortalama arter basıncı ölçümlerinde anlamlı fark bulunamamışken 30, 35, 40, 45. dakika ölçümlerinde ise spinal anestezi hastalarının ortama arter basınçları anlamlı düşük bulunmuştur (9). Sungur ve arkadaşlarının yaptığı çalışmada spinal anestezide efedrin ihtiyacı \%40 olarak tespit edilmişken bu oran genel anestezide sadece \%1.7'dir (10). Biz çalışmamızda spinal anestezide hipotansiyon insidansını \%47.1 olarak tespit ettik. Çalışmamızda hipotansiyon gelişen tüm hastalara efedrin uygulandı. Bizim çalışmamızda sistolik kan basıncı kıyaslandığında sadece beşinci dakika ölçümünde spinal anestezide anlamlı düşüş tespit edildi. Ayrıca çalışmamizda diyastolik ve ortalama kan basıncı değerlerinin spinal anestezide genel anesteziye oranla beşinci, onbeşinci ve otuzuncu dakikalardaki ölçümlerde anlamlı düşük olduğu tespit edildi.

Fassoulaki ve arkadaşlarının yapmış oldukları çalışmada spinal ve genel anestezi bulantı ve kusma görülme yönünden kıyaslanmış ve anlamlı fark bulunamamıştır (11). Biz de literatürle uyumlu olarak fark bulamadik.

Anestezi öncesi hastaların endişe düzeylerinin hastaların memnuniyetini çok etkilediğini düşünerek bunun nedenlerini araştırdığımız çalışmamızda anesteziyle ilgili endişe edilen nedenler içinde en sık ameliyat sonrası uyanmamak (\%53,5), yoğun bakımda kalmak (\%18.8), ameliyat sonras1 ağrı (\%11.9) tespit edilmiştir. Shevde ve Panagoulos'un yaptıkları çalışmada anesteziye bağlı en sık endişe nedenleri anestezistin bilgi yetersizliği (\%45), anestezistin deneyim eksikliği (\%43), uyanamamak (\%37) ve postoperatif ağrı (\%34) olarak sıralanırken (12), Şekerci ve arkadaşlarının çalışmasinda, ameliyat sonrası uyanamamak $(\% 51,9)$, herhangi bir aksilik olması $(\% 22,1)$, anestezistin tecrübesizliği $(\% 7,8)$ ve ameliyat sırasında ağrı duymak $(\% 3,8)$ en sık nedenler olarak bildirilmiştir (13).

Postoperatif komplikasyonlardan bulant1-kusma, bel sirt ağrısı ve nefes darlığı gelişen hastaların QoR-40 değerlerinin bu komplikasyonların görülmediği hastalardan anlamlı olarak düşük olduğu görüldü.

Spinal ve genel anesteziyi hasta memnuniyeti açısından karşılaştırdığımızda; spinal anestezi ile opere olan hastaların memnuniyet ölçeği ortalama puanları 175.3 \pm 7.7 iken genel anestezide $170.6 \pm 11.06$ bulunmuş olup bu fark istatistiksel olarak anlamlıdır. Fassoulaki ve arkadaşlarının yapmış oldukları çalışmada kombine spinal-epidural anestezide hasta memnuniyeti genel anesteziye kıyasla anlamlı yüksek bulunmuşken (11), Lertakyamanee ve arkadaşlarının çalışmasında ise spinal, epidural ve genel anestezi anne memnuniyeti aç1sından karşılaştırılmış ve anlamlı fark bulunamamıştır (14). Yine bizim sonuçlarımızın aksine Kızılkaya ve arkadaşlarının yaptıkları çalışmada spinal ve genel anestezi yöntemleri karşılaştırılmış ve memnuniyet üzerine etkisi bulunmamıştır (15).

Çalışmamızın kısıtlılıkları hastalarımızın postoperatif ağrı değerlendirmesini yapmamış olmamız ve genel anestezi tercih nedeninin sorgulanmaması olabilir.Postoperatif memnuniyeti etkileyen en önemli faktörlerden biride ağrı kontrolüdür.

Sonuç olarak; preoperatif anksiyete düzeyinin yüksekliğihastaların genel anesteziyi tercih etmelerine neden olmaktadır.Preoperatif gebelerin anestezi ile ilgili endişeleri belirlenip daha etkin bir bilgilendirme yapılarak, gebelerin sezaryen ameliyatlarında kendi ve bebekleri için daha güvenli olan spinal anestezi tercihlerinin artırılabileceğini, daha iyi bir deneyim sunarak memnuniyetlerinin artırılabileceğini düşünmekteyiz.

Çıkar Çatışması Beyanı: Makale yazarları aralarında herhangi bir çıkar çatışmasınınolmadığını beyan ederler.

Araştırmacıların Katkı Oranı Beyan Özeti: Yazarlar makaleye eşit katkı sağlamış olduklarını beyan ederler.

\section{KAYNAKLAR}

1. Sağlık İstatistikleri Yıllığ 2019 Haber Bülteni; 2020. p. 2.

2. Sak S, Peker N, Uyanıkoğlu H, Binici O, İncebıyık A, Sak ME. Elektif Sezaryende Genel Anestezi'mi, Spinal Anestezi’mi Uygulanmalı? Zeynep Kamil Tip Bül 2018;49(1):4448

3. John S, McDonald, Ralph W, Yarnell. FRCP Current Obst and Gyn 2010;441 
4. Morgan EG, Mikhail SM, Murray SM. Klinik Anesteziyoloji: Nonvolatil Anestezik Ajanlar. Güneş Kitabevleri 2008;8:179-204

5. Morgan GE, Mikhail MS, Murray MJ. Obstetrik anestezi, Edt: Tulunay M, Cuhruk H. Clinical Anaesthesiology. Klin Anest. Çev. 4. Baskı. Öncü basımevi, Ankara 2008;890- 921

6. Maheshwari D, Ismail S. Preoperative anxiety in patients selecting either general or regional anesthesia for elective cesarean section. J Anaesthesiol Clin Pharmacol. 2015;31(2): 196-200

7. Jlala HA, French JL, Foxall GL, Hardman JG, Bedforth NM. Effect of preoperative multimedia information on perioperative anxiety in patients undergoing procedures under regional anaesthesia. British Jour of Anaesth 2010;104(3):369-74

8. Havas F, Sungur MO, Yenigün Y, Karadeniz M, Kılıç M, Seyhan TÖ. Elektif sezaryen ameliyatlarında spinal anestezi genel anesteziye kıyasla hastanede kalış süresini k1saltmaktadır. Ağrı 2013;25(2):55-63

9. Purtuloğlu T, Özkan S, Teksöz E, Dere K, Şen H, Yen T, et al. Elektif sezaryen uygulanan olgularda genel ve spinal anestezinin maternal ve fetal etkilerinin karşılaştırılması. Gülhane Tip Derg 2008;50:91-97

10. Sungur MO, Havas F, Karadeniz M, Acar U, Altun D, Seyhan TÖ. Elektif Sezaryen Ameliyatlarında Anestezi Seçiminin Ameliyat Odası Kullanım Süresine Etkisi: Spinal mi Genel mi? Türk Anest Rean Der 2012;40(3):136-143

11. Fassoulaki A, Staikou C, Melemeni A, Kottis G, Petropoulos G. Anaesthesia preference, neuraxial vs general, and outcome after caesarean section. Jour of Obst and Gyn 2010;30(8): 818-821

12. Shevde K, Panagopoulos G. A survey of 800 patients knowledge, attitudes and concerns regarding anesthesia. Anesth Analg 1991;73:190-198.

13. Şekerci S, Akpek E, Göktuğ A, Çetinsoy BC, Karabıyık L, Erdemli Ö ve ark. Hasta ve yakınları ile toplumun farklı kesimlerinin anestezi ve uygulamaları konusundaki bilgi ve davranışları. Anest Derg 2001;9(1):48-51.

14. Lertakyamanee J, Chinachoti T, Tritrakarn T, Muangkasem J, Somboonnanonda A, Kolatat T. Comparison of general and regional anesthesia for cesarean section: success rate, blood loss and satisfaction from a randomized trial. J Med Assoc Thai 1999;82:672-80.

15. Kızılkaya S, Tavlan A, Hacıbeyoğlu G, Arıcan Ş, Uzun ST. Elektif Sezaryen Ameliyatlarında Kullanılan Anestezi Yönteminin Ağrı Anksiyete ve Hasta Memnuniyeti Üzerine Etkisi. Selçuk Med J 2020;36(3):192-198 